Check for updates

Cite this: RSC Adv., 2019, 9, 38697

Received 25th August 2019

Accepted 14th November 2019

DOI: $10.1039 / c 9 r a 06689 f$

rsc.li/rsc-advances

\section{Immunochromatographic assay for T-2 toxin based on luminescent quantum dot beads}

\author{
Zhiwei Qie, Di $\dagger^{\mathrm{a}}$ Jinmiao Shi, $\uparrow^{\mathrm{a}}$ Wenliang Yan, ${ }^{\mathrm{a}}$ Zichen Gao, ${ }^{\mathrm{b}}$ Wu Meng, ${ }^{\mathrm{b}}$ Rui Xiao*a \\ and Shengqi Wang*a
}

A quantum dot bead based immunochromatographic assay (QB-ICA) system was established for T-2 toxin (T-2), which widely occurs in agriculture and could be used as a potential biological warfare agent. After optimization, the dynamic linear detection range of T-2 calculated from a calibration curve was from 0.12 to $0.67 \mathrm{ng} \mathrm{mL}^{-1}$ and the limit of detection (LOD) was $0.08 \mathrm{ng} \mathrm{mL}^{-1}$, which is lower than those of the ICA based on colloidal gold nanoparticles or a fluorescent material or an antibody-based biochip in other reports. The performance and practicability of the established ICA system were validated with a commercial ELISA kit and the two methods were comparable. The proposed QB-ICA for T-2 could be an alternative for rapid, sensitive, and quantitative on-site detection of this toxin in biosafety monitoring in agriculture and for susceptibility testing of the potential release of this biological warfare agent.

\section{Introduction}

T-2 toxin, produced particularly by the fusarium species, is a heat-stable trichothecene and widely occurs in crops such as maize, wheat, oat, etc. ${ }^{1}$ Trichothecenes from livestock and poultry animals fed with trichothecenes-contaminated feed, have the potential to enter human food chains through milk, meat and eggs. ${ }^{2}$ It has been proved that, through inhibiting protein synthesis, T-2 toxin could cause alimentary toxic aleukia and diverse pathologies, including lesions in lymphoid, hematopoietic, and gastrointestinal tissues and functional inhibition of reproductive organ functions. ${ }^{3-5}$ In recent years, an increasing amount of attention has been attached to biosafety in agriculture and the T-2 toxin has been regarded as one of the most dangerous contaminants by the European Food Safety Authority (EFSA). ${ }^{6}$ Furthermore, after the 9/11 attack, the possibility of bioterrorism has become more credible. In absolute amount during dermal exposure, T-2 toxin may be nearly 100 times more potent than mustard and can be deployed as biological warfare agent (BWA) in various forms. ${ }^{7}$ Thus, considering the universal existence of $\mathrm{T}-2$ toxin, its adverse effects and potential risk in bioterrorism attack, there is an urgent need to investigate effective approaches for T-2 toxin detection and on-site distinguish of the nature of the "supposed released BWA".

\footnotetext{
${ }^{a}$ Beijing Institute of Radiation Medicine, Beijing 100850, PR China. E-mail: ruixiao203@sina.com; sqwang@bmi.ac.cn; Tel: +86 010 66931422; +86 010 66932211

${ }^{b}$ Center for Diseases Prevention and Control of Rocket Force, China

$\dagger$ These authors contribute equally to this work.
}

Several analytical methods have been used for the determination of T-2 toxin, such as high-performance liquid chromatographytandem mass spectrometry, ${ }^{6}$ ultra-performance liquid chromatography (UPLC), ${ }^{8}$ high performance liquid chromatographic-mass spectrometry (LC-MS), ${ }^{9}$ ultra-performance liquid chromatography tandem mass spectrometry (UPLC-MS/MS), ${ }^{10}$ gas chromatographytandem mass spectrometry, ${ }^{11}$ competitive enzyme-linked immunosorbent assay, ${ }^{12}$ immunomagnetic bead-based enzyme-linked immunosorbent assay (IMB-ELISA), ${ }^{13}$ fluorescence assay, ${ }^{14}$ fluorescence polarization immunoassay (FPI). ${ }^{15}$ Although chromatographic methods and traditional ELISA are usually very accurate and highly selective, these methods are relatively sophisticated, tedious and expensive, which cannot meet the requirement of onsite fast detection.

In contrast, immunochromatographic system assay (ICA) based on luminescence materials and colored nanoparticles offers rapid, specific and reliable means of detection. ${ }^{16,17}$ Labels such as colloidal gold particles, magnetic nanoparticles, upconverting phosphors, colloidal carbon, time-resolved fluorescence, organic or inorganic dye-doped nanoparticles and quantum dots (QDs) have been utilized to improve sensitivity. Among which QDs has become one of the ideal fluorescent labels and quantum dots nanobeads $(\mathrm{QB})$, prepared by doping of numerous QDs inside polybeads, further improved the sensitivity of ICA substantially ${ }^{18-20}$ But ICA detection of T-2 toxin based on QB has not been reported. Furthermore, when $\mathrm{T}-2$ is used as BWA, water is one the most likely contaminated target harming militant, T-2-positive water is also probable. For food and related products, T-2 toxin is widely occurred in oat, wheat and beer. ${ }^{21}$

An ICA for T-2 was established using QB as label. The fluorescence intensity (FI) was read out by a portable system reader. 
The limit of detection (LOD) was compared among ICA using colloidal gold nanoparticles (GNPs), luminescence materials and antibody-based biochip. The results proved the advantage of the proposed QB-ICA system with comparable performance to conventional ELISA methods. Hence, the proposed QB-ICA offers great potential for quantitative detection of T-2 and could be used as an alternative for rapid susceptibility testing of "supposed released BWA".

\section{Experimental section}

\section{Materials}

$N$-(3-(Dimethylamino)propyl)- $N^{\prime}$-ethylcarbodiimide hydrochloride $(\mathrm{EDC} \cdot \mathrm{HCl})$, Tween-20, T-2 standard and its metabolites HT2, T-2 triol and deoxynivalenol (DON), zearalenone (ZEN), and fumonisin $\mathrm{B}_{1}$ (FMB1) were purchased from J\&K Scientific Ltd. (Shanghai, China). Anti-T-2 mAbs, T-2-OVA conjugates, goat anti-mouse IgG antibodies and the commercial T-2 ELISA kit were purchased from Shandong Landu Bio-Science \& Technology Co., Ltd. (Shandong, China). Carboxylate functionalized QBs with excitation wavelength $365 \mathrm{~nm}$ and emission wavelength of $610 \mathrm{~nm}$ (Cat: FM610C) were purchased from Beijing Najing Biological Technology Co., Ltd. (Beijing, China). Protein stabilizer solution (Cat: PR-SS-002) were purchased from Huzhou Yingchuang Biological Technology Co., Ltd. (Huzhou, China). All of the other reagents were of analytical grade and purchased from the National Pharmaceutical Group Chemical Reagent Co., Ltd. (Shanghai, China). Tap water was collected in lab. The nitrocellulose (NC), sample pad (glass fiber membrane), absorbent pad and polyvinylchloride backing card were obtained from Schleicher and Schuell $\mathrm{GmbH}$ Goldbio Tech., Co. (Shanghai, China).

\section{Apparatus}

All buffer solutions were prepared with ultrapure water prepared by a Milli-Q purification system (Millipore Co., Bedford, MA, USA). AirJet Quanti 3000 ${ }^{\mathrm{TM}}$ and BioJet Quanti 3000 ${ }^{\mathrm{TM}}$ were supplied by BioDot (Irvine, CA). An automatic cutter was purchased from Shanghai Jinbiao Biotechnology Co., Ltd. (Shanghai, China) and employed. The ICA strip scan reader was provided by Beijing Najing Biological Technology Co., Ltd. (Beijing, China).

\section{Preparation of the QB-mAbs and fabrication of QB-ICA system}

Through active ester method, the anti-T-2 mAbs was covalently conjugated to QBs. ${ }^{22}$

The composition of the QB-ICA system is shown in Fig. 1. The ICA system contains three parts: sample pad (glass fiber), NC membrane, and absorbent pad. The NC membrane was located in the middle of the PVC backing card, and the sample and absorption pads were fixed on both ends with a nearly $2 \mathrm{~mm}$ overlap without any pretreatment. The T-2-OVA $(0.5 \mathrm{mg}$ $\left.\mathrm{mL}^{-1}\right)$ and goat anti-mouse IgG antibodies $\left(0.5 \mathrm{mg} \mathrm{mL}^{-1}\right)$ were respectively sprayed onto the NC membrane as test and control lines at densities of $3 \mu \mathrm{L} \mathrm{cm}{ }^{-1}$. The assembled QB-ICA system was then dried at $37^{\circ} \mathrm{C}$ for $2 \mathrm{~h}$ and cut into $3.5 \mathrm{~mm}$ wide system, stored until use.

\section{Quantitative procedure of QB-ICA system}

The ICA system was based on the principle of a competitive recognition, in which the free $\mathrm{T}-2$ toxin and the immobilized antigens (T-2-OVA) on the test line ( $\mathrm{T}$ line) on NC membrane competitively binding to QB-labeled mAbs when the sample solution flow through the T line. For T-2 positive sample, QBmAb conjugated with T- 2 , forming the QB-mAb-T-2 complex, leading to fewer QB-mAb binding to the antigens fixed on the $\mathrm{T}$ line. Thus, the fluorescence intensity on the $\mathrm{T}$ line $\left(\mathrm{FI}_{\mathrm{T}}\right)$ was weaker. Therefore, $\mathrm{FI}_{\mathrm{T}}$ was inversely proportional to the concentration of $\mathrm{T}-2$ in the sample, based on which the calibration curve was established and the T-2 concentration was calculated accordingly. The sample solution was prepared by mixing QB-mAbs probe at dilution ratio of $1: 1000$ and $100 \mu \mathrm{L}$ of spiked solution in a micro hole. Then the QB-ICA strip was dipped into the mixture and the signal was collected. The standard T-2 solutions were prepared by diluting stock $\mathrm{T}-2$ solution $\left(100 \mathrm{ng} \mathrm{mL}^{-1}\right)$ in $\mathrm{PB}$ containing $5.0 \%$ methanol at $\mathrm{pH} 5.6$ to a final concentration of 0 (as negative control), 0.035, 0.07, 0.15, 0.31, 0.62, 1.25, and $2.5 \mathrm{ng}$ $\mathrm{mL}^{-1}$. Detection results was compared and summarized between T-2 spiked samples by QB-ICA in this work and

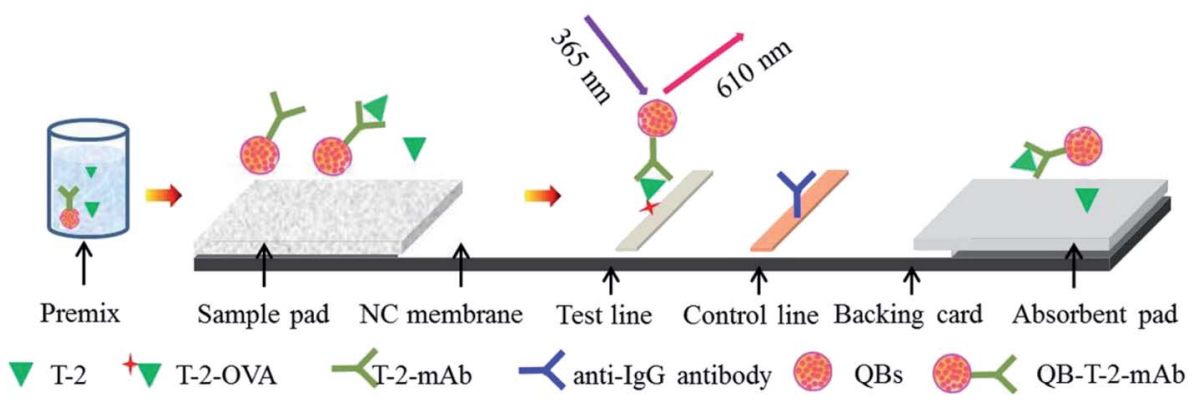

Fig. 1 Schematic diagram of detection of T-2 toxin using QB-ICA. T-2 and QB-T-2-mAb premixed and dropped onto the sample pad. When the mixture flows through the test line, the T-2 and T-2-OVA competitively binds for the binding site on QB-T-2-mAb. The more T-2 exist, the less QB-T-2-mAb combine with T-2-OVA and the weaker fluorescence intensity was observed on the test line. The un-combined QB-T-2-mAb would be captured by the anti-lgG antibody on the control line. 
A
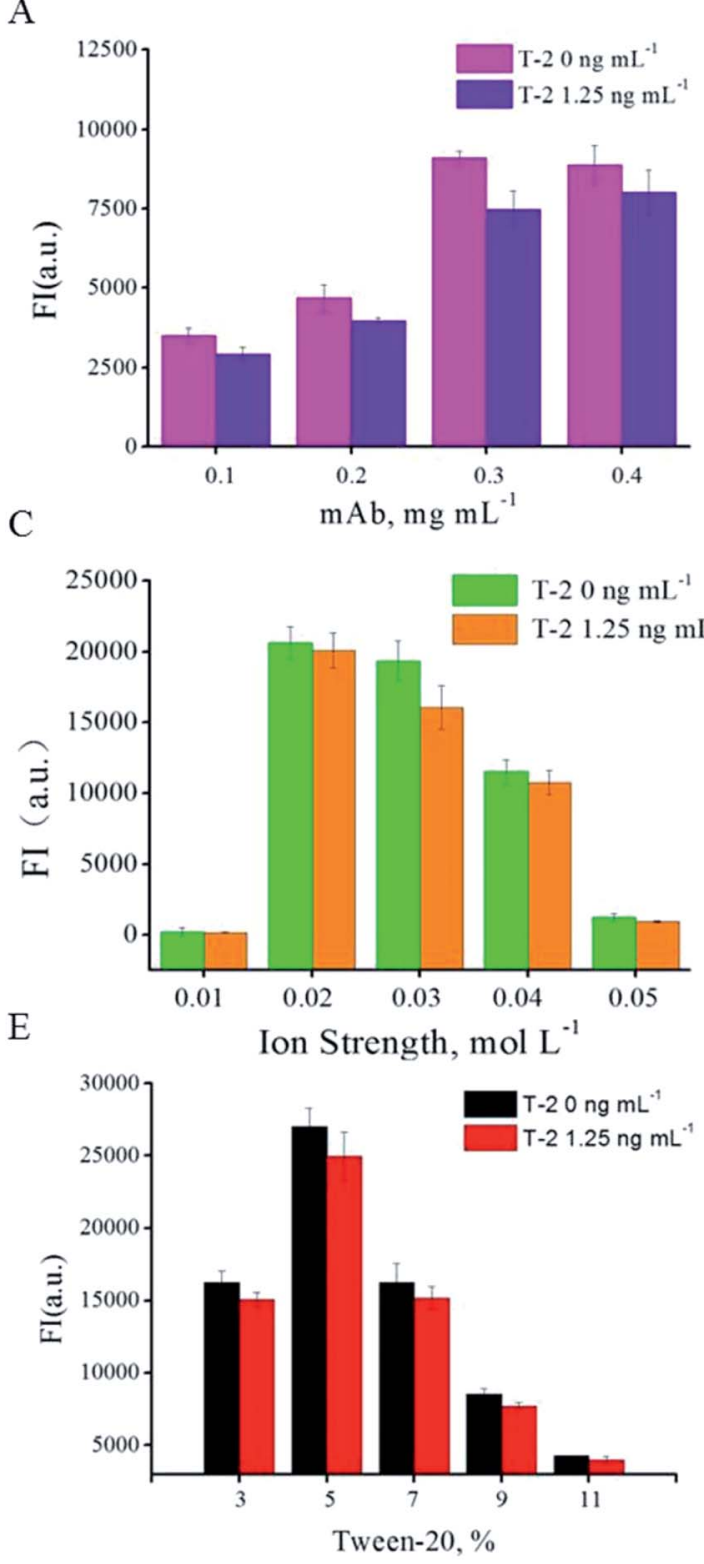

B
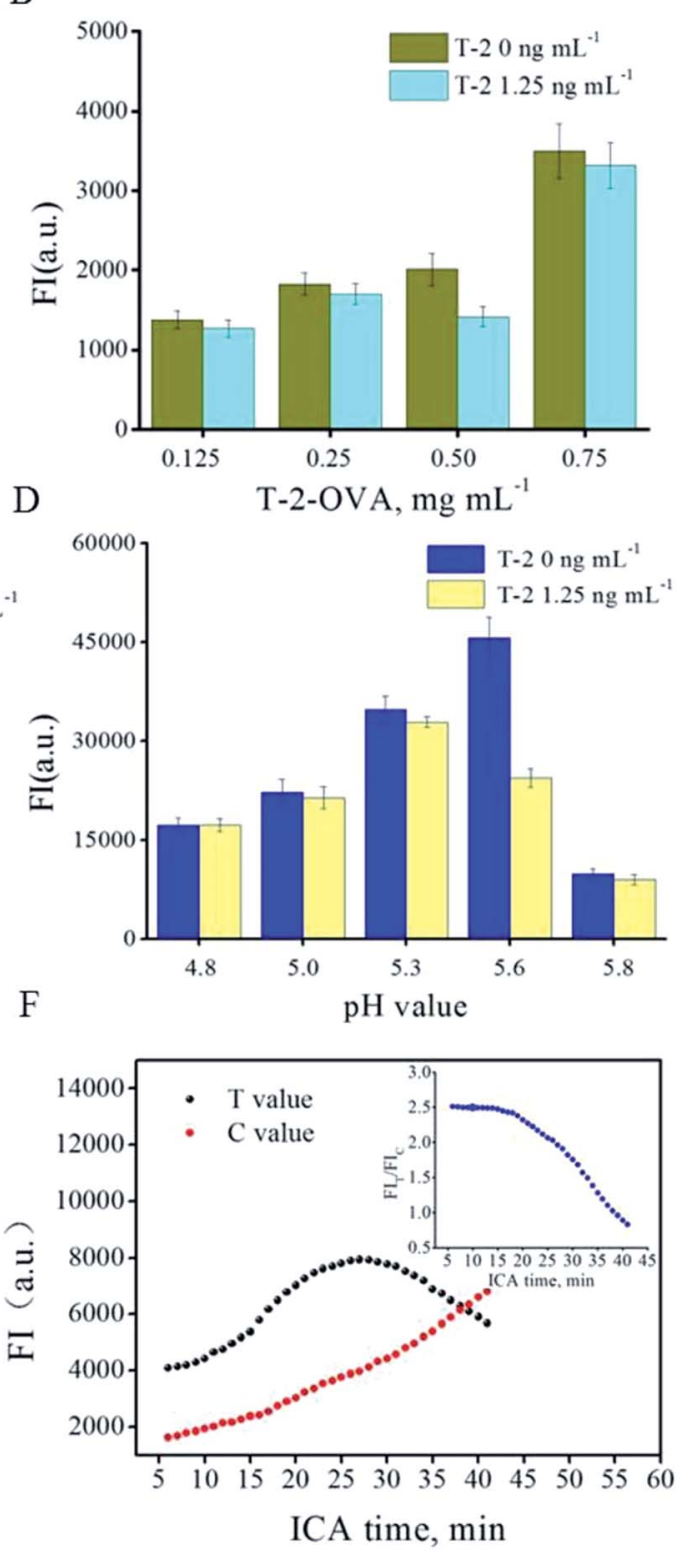

Fig. 2 (A) Estimation of the optimal labeling amount of anti-T-2-mAb on QBs. (B) Optimization of T-2-OVA concentration on the T line. (C) Effect of ion strength on FI. (D) Effect of $\mathrm{pH}$ value on FI. (E) Optimization of optimal Tween-20 concentration in the ICA system. (F) Immunoreaction dynamics of $\mathrm{FI}_{\mathrm{T}}, \mathrm{FI}_{\mathrm{C}}$, and $\mathrm{FI}_{\mathrm{T}} / \mathrm{FI}_{\mathrm{C}}$ (inset). Optimization from $\mathrm{A}$ to $\mathrm{E}$ were carried out in competitive inhibition mode with $\mathrm{T}$-2 spiked concentration of 0 and $1.25 \mathrm{ng} \mathrm{mL}^{-1}$.

reported T-2-detecting ICA using GNPs and the assay using fluorescent material and biochip. Accuracy and precision analysis was evaluated in triplicate by using standard solution samples with spiked T-2 concentrations of $0.15,0.30$, and $0.60 \mathrm{ng} \mathrm{mL}^{-1}$.

\section{Spiked tap water and beer samples and pretreatment}

T-2 free tap water samples were collected from our lab. All samples were filter by $0.22 \mu \mathrm{m}$ PTFE filter (Phenomenex, Torrance, $\mathrm{CA}$ ) prior to T-2 ICA detection and mix with equal volume of $\mathrm{PB}(0.06 \mathrm{M}, \mathrm{pH}$ 5.6) containing $5 \%$ sucrose, $2 \%$ fructose, $1 \%$
PEG 20000, and 10\% Tween-20. T-2 free beer samples were collected from local market. The samples were degassed at $60{ }^{\circ} \mathrm{C}$ for $60 \mathrm{~min}$ and filtered, followed by 10 times dilution with PB mentioned above.

\section{Comparative evaluation}

Comparative evaluation was carried out between ICA results using proposed QB-ICA and that using commercial ELISA kit. Both blank tap water and beer samples were spiked with T-2 concentrations over the range of $0.3-1.2 \mathrm{ng} \mathrm{mL}^{-1}$. All tests were carried out in triplicate. 


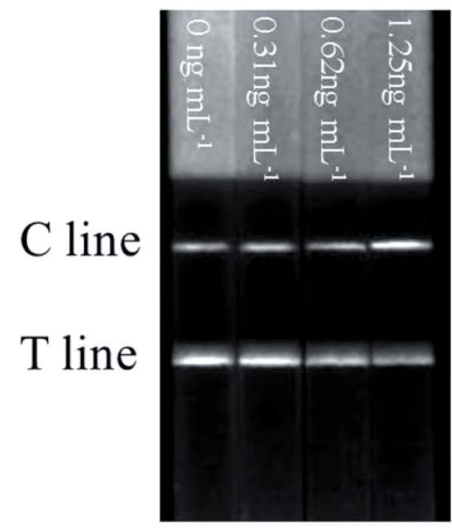

A

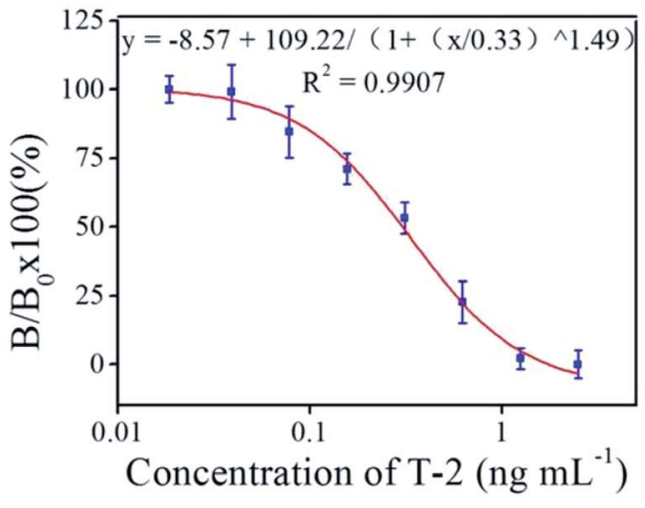

B

Fig. 3 (A) Photo of ICA strips with different concentrations of T-2 under $365 \mathrm{~nm}$ UV excitation by gel imager. (B) Standard inhibition curve for T-2 was obtained by plotting the normalized signal $B / B_{0} \times 100 \%$ against the logarithm of $\mathrm{T}-2$ concentration. Data were carried out in triplicate.

\section{Results and discussion}

\section{Optimization of the QB-ICA system}

Factors effecting ICA results were optimized, including labeling amount of anti-T-2-mAb on the surface of the QB, ion strength, $\mathrm{pH}$ value, Tween-20 concentration, QB-mAbs dilution ratio and ICA time interval. The competitive inhibition mode was carried out to screen the optimal parameters. In preliminary experiment, the T-2 spiked concentration was applied at 5, 2.5, 1.25, $0.625 \mathrm{ng} \mathrm{mL}$, and obvious inhibition could be observed at $1.25 \mathrm{ng} \mathrm{mL} \mathrm{mL}^{-1}$. Higher spiked concentration leads to insignificant inhibition increment and lower spiked concentration was adverse for the optimization of other parameters. Thus, the spiked concentration of $1.25 \mathrm{ng} \mathrm{mL}^{-1}$ was chosen and applied in following optimization. (data not shown) The anti-T-2 mAb from 0.1 to $0.4 \mathrm{mg}$ was conjugated with $1 \mathrm{~mL}$ of QB. The resultant QB-mAbs were then run on the ICA system in competitive mode and the fluorescent intensity was recorded. Fig. $2 \mathrm{~A}$ shows that the strongest $\mathrm{FI}_{\mathrm{T}}$ and most obvious inhibition were observed at anti-T-2 mAb amount of $0.3 \mathrm{mg}$ per $\mathrm{mL}$ of $\mathrm{QB}$ and T-2 spiked concentration of 0 and $1.25 \mathrm{ng} \mathrm{mL}^{-1}$. Higher or lower concentration of anti-T-2 mAb would lead to weaker $\mathrm{FI}_{\mathrm{T}}$ and inhibition. Thus, the proper coupling amount was $0.3 \mathrm{mg}$ per $\mathrm{mL} \mathrm{QB}$. Likewise, T-2-OVA on $\mathrm{T}$ line of $0.5 \mathrm{mg} \mathrm{mL}^{-1}$ is the most sensitive concentration to spiked T-2 (Fig. 2B). Ion strength of $0.03 \mathrm{~mol} \mathrm{~L}^{-1} \mathrm{~PB}$ solutions was chosen (Fig. 2C). $\mathrm{pH}$ of 5.6 was selected (Fig. 2D). Surfactant Tween-20 of $5 \%$ (v/v) was chosen (Fig. 2E) and methanol concentration of 5\% implied to resolve T-2. The less use of QB-mAbs was beneficial for the higher sensitivity. But the fluorescence intensity must be readable. As a compromise, QB-mAb dilution ratio was chosen at $1: 1000$.

Different amount of antibody-modified quantum dot beads was applied at different parameter in order to clearly show the inhibition difference under different level at the same T-2 spiked concentration. As a result a significant difference of fluorescence intensity in different parameter optimization is observed. Under the optimized parameters, immunological kinetics analysis was introduced to evaluate the ICA process. ${ }^{23,24}$ Fig. $2 \mathrm{~F}$ indicated that the FIs on $\mathrm{T}$ line increase until $25 \mathrm{~min}$, and that on $\mathrm{C}$ line increase continuously during the observation period. While, $\mathrm{FI}_{\mathrm{T}} / \mathrm{FI}_{\mathrm{C}}$ ratio reached a relative constant value in the first $15 \mathrm{~min}$ and decrease swiftly afterward. $\mathrm{FI}_{\mathrm{T}} / \mathrm{FI}_{\mathrm{C}}$ ratio was stable until $15 \mathrm{~min}$, while $\mathrm{FI}_{\mathrm{T}}$ was nearly $62 \%$ of that at $25 \mathrm{~min}$. Stronger $\mathrm{FI}_{\mathrm{T}}$ absolute value means less QB-mAb consumption and lower LOD. Thus, all the following FIs were collected from $\mathrm{FI}_{\mathrm{T}}$ value at $25 \mathrm{~min}$, based on which the calibration curve was established.

\section{Analytical performance of the QB-ICA system}

Fig. 3A showed that the $\mathrm{FI}_{\mathrm{T}}$ was weaker as increasing $\mathrm{T}-2$ spiked concentration (from left to right). Calibration curve was established based on the competitive inhibition rates, plotting the $B /$

Table 1 Comparison of QB-ICA with other methods for T-2 toxin detection

\begin{tabular}{lllll}
\hline Methods & Analytical range $\left(\mathrm{ng} \mathrm{mL} \mathrm{mL}^{-1}\right)$ & LOD $\left(\mathrm{ng} \mathrm{mL} \mathrm{m}^{-1}\right)$ & $\mathrm{IC}_{50}\left(\mathrm{ng} \mathrm{mL}^{-1}\right)$ & $\mathrm{Reference}$ \\
\hline QB-ICA & $0.12-0.67$ & 0.08 & 0.30 & This work \\
GNPs-ICA & $0.25-5$ & 0.15 & $\mathrm{NR}^{a}$ & Kong et al., 2016 (ref. 19) \\
Fluorescent bioassay & $0.23-17.49$ & 0.19 & $\mathrm{NR}$ & He et al., 2019 (ref. 27) \\
Antibody-based biochip & $0.4-18.8$ & 0.4 & 2.5 & Schulz et al., 2019 (ref. 28)
\end{tabular}

${ }^{a}$ Not reported. 
$B_{0} \times 100 \%$ against the logarithm concentrations of the stan-

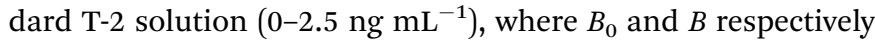
represent $\mathrm{FI}_{\mathrm{T}}$ of the negative sample and a $\mathrm{T}-2$ spiked sample in standard solution $\left(2.5 \mathrm{ng} \mathrm{\textrm {mL } ^ { - 1 }}\right.$ ). A linear range from 0.13 to $0.67 \mathrm{ng} \mathrm{mL} \mathrm{m}^{-1}$ was observed (Fig. 3B). All measurements were carried out in triplicate. ICA results of spiked standard solutions were also compared among proposed ICA based on GNPs and fluorescent materials and antibody-based biochip, as shown in Table 1.

The LOD was defined as the T-2 concentration, which leads to $10 \%$ inhibition $\left(\mathrm{IC}_{10}\right)$ in this study. Under standard solution and optimal experimental conditions, the LOD of constructed calibration curve was $0.08 \mathrm{ng} \mathrm{mL}^{-1}(n=3)$, which is about 2 times lower than those of the ICA based on GNPs (LOD $=0.15$ $\mathrm{ng} \mathrm{mL}^{-1}$ ), 2.5 times lower than those of assay using fluorescent material $\left(\mathrm{LOD}=0.19 \mathrm{ng} \mathrm{\textrm {mL } ^ { - 1 }}\right)$.

The cross-reaction (CR), representing the specificity of the QB-ICA system was evaluated among HT-2, T-2 triol, DON, ZEN, and $\mathrm{FMB}_{1}$. CR value was calculated through the following equation: $\mathrm{CR} \%=\left[\left(\mathrm{IC}_{50} \mathrm{~T}-2\right) /\left(\mathrm{IC}_{50}\right.\right.$ analog $\left.)\right] \times 100 .{ }^{25}$ The results showed that the structural analogues HT-2, T-2 triol show CR of $23.08 \%$ and $6.06 \%$ and that of its functional analogues DON, ZEN, and $\mathrm{FMB}_{1}$ lower than 0.01 , which implies the proposed ICA is specific (Table 2).

Recovery of the intra- and inter-assay was evaluated to characterize the accuracy and precision of the proposed QB-ICA. Recovery of intra-assay was calculated by three replicates of spiked $\left(0.15,0.3,0.6 \mathrm{ng} \mathrm{mL}^{-1}\right)$ standard solutions, and the inter-assay was investigated through three replicates of intraassay. As can be seen in Table 3, the average recoveries ranged from 81.25 to $115.95 \%$ and are acceptable for ICA quantitative analysis. ${ }^{26,27}$

Table 2 Cross reaction of the QB-ICA

\begin{tabular}{lll}
\hline Pretreatment & IC $_{50}$ & CR \\
\hline T-2 & 0.30 & 100 \\
HT-2 & 1.26 & 23.08 \\
T-2 tirol & 4.95 & 6.06 \\
DON & - & $<0.01$ \\
ZEN & - & $<0.01$ \\
FMB $_{1}$ & - & $<0.01$
\end{tabular}

Table 3 Precision and stability of the QB-ICA in T-2-spiked standard solution

\begin{tabular}{|c|c|c|c|c|c|c|}
\hline \multirow{2}{*}{$\begin{array}{l}\text { Spiked T-2 } \\
\left(\text { ng mL }{ }^{-1}\right)\end{array}$} & \multicolumn{3}{|c|}{ Intra-assay } & \multicolumn{3}{|c|}{ Inter-assay } \\
\hline & $\operatorname{Mean}^{a}$ & Recovery (\%) & CV (\%) & Mean & Recovery (\%) & CV (\%) \\
\hline 0.15 & 0.17 & 115.95 & 4.54 & 0.16 & 107.22 & 3.29 \\
\hline 0.30 & 0.24 & 81.25 & 5.72 & 0.29 & 98.25 & 4.08 \\
\hline 0.60 & 0.54 & 90.74 & 4.26 & 0.53 & 87.63 & 5.29 \\
\hline
\end{tabular}

${ }^{a}$ Mean value of 3 replicates at each spiked concentration.
Table 4 Determination of T-2 spiked tap water with QB-ICA system and ELISA kit

\begin{tabular}{|c|c|c|c|c|}
\hline $\begin{array}{l}\text { Spiked T-2 } \\
\left(\text { ng mL }^{-1}\right)\end{array}$ & $\begin{array}{l}\text { QB-ICA }^{a, b} \\
\left(\mathrm{ng} \mathrm{mL}^{-1}\right)\end{array}$ & $\begin{array}{l}\text { ELISA kit } \\
\left(\mathrm{ng} \mathrm{mL}^{-1}\right)\end{array}$ & $\begin{array}{l}\text { QB-ICA }^{c} \\
\left(\mathrm{ng} \mathrm{mL}^{-1}\right)\end{array}$ & $\begin{array}{l}\text { ELISA kit } \\
\left(\mathrm{ng} \mathrm{mL}^{-1}\right)\end{array}$ \\
\hline 0.30 & $0.30 \pm 0.007$ & $0.30 \pm 0.045$ & $0.29 \pm 0.019$ & $0.31 \pm 0.015$ \\
\hline 0.60 & $0.53 \pm 0.026$ & $0.57 \pm 0.033$ & $0.55 \pm 0.031$ & $0.59 \pm 0.030$ \\
\hline 1.20 & $1.40 \pm 0.053$ & $1.12 \pm 0.029$ & $1.19 \pm 0.042$ & $1.21 \pm 0.038$ \\
\hline
\end{tabular}

\section{Determination of T-2 in tap water and beer}

The proposed QB-ICA ( $\mathrm{IC}_{50}=0.30 \mathrm{ng} \mathrm{mL}^{-1}$ ) system was compared with a commercial ELISA kit $\left(\mathrm{IC}_{50}=0.36 \mathrm{ng} \mathrm{mL}^{-1}\right)$ by respectively analyzing three T-2 spiked tap water or beer samples. The results showed in Table 4 suggest that the two methods showed good agreement. For beer sample, the matrix effect to ICA results was negligible. The proposed QB-ICA for spiked tap water samples took nearly 25 min to complete one sample analysis, while traditional ELISA took $90 \mathrm{~min}$. For spiked beer samples, degassing and dilution is necessary. And the proposed ICA was more easy-to-use and results validated the applicability of the established QB-ICA method.

\section{Conclusions}

A QB-ICA for T-2 toxin was established. The proposed QB-ICA system was systematically optimized and beneficial to improve the application of ICA in biosafety. Under optimal conditions, the LOD for T-2 in standard solutions was $0.08 \mathrm{ng}$ $\mathrm{mL}^{-1}$, improved by approximately 2 times compared with ICA for T-2 toxin based on GNPs, and 2.5 times better than that of bioassay using fluorescent material and 5 times better than other antibody-based biochip, as is shown in Table 1. The CVs for intra- and inter-assay representing the accuracy and precision were below $10 \%$, in the acceptable extent. The recoveries based on the QB-ICA system detecting spiked tap water samples were comparable with those based on a commercial ELISA kit. In conclusion, the proposed QB-ICA system could be an alternative for the on-site quantitative detection of $\mathrm{T}-2$ toxin contamination in biosafety in agriculture and a novel method for rapid susceptibility detection of "supposed released BWA".

\section{Conflicts of interest}

The authors declare that the research was conducted in the absence of any commercial or financial relationships that could be constructed as a potential conflict of interest.

\section{Acknowledgements}

We thank colleagues for making great efforts to this manuscript. This work was supported by Major Infectious Diseases Such as AIDS and Viral Hepatitis Prevention and Control 
Technology Major Projects (2018ZX10712-001) and the Major Projects (No. AWS16J020).

\section{References}

1 L. Chen, Y. Tian, B. Sun, J. Wang, Q. Tong and Z. Jin, Food Chem., 2017, 233, 525-529.

2 Z. Zou, Z. He, H. Li, P. Han, J. Tang, C. Xi, Y. Li, L. Zhang and X. Li, Meat Sci., 2012, 90, 613-617.

3 M. Adhikari, B. Negi, N. Kaushik, A. Adhikari, A. A. AlKhedhairy, N. K. Kaushik and E. H. Choi, Oncotarget, 2017, 8, 33933-33952.

4 K. Schulz, C. Pöhlmann, R. Dietrich, E. Märtlbauer and T. Elßner, Front. Chem., 2019, 7, 31.

5 G. Yuan, Y. Wang, X. Yuan, T. Zhang, J. Zhao, L. Huang and S. Peng, J. Environ. Sci., 2014, 26, 917-925.

6 Y. Sun, G. Zhang, H. Zhao, J. Zheng, F. Hu and B. Fang, J. Chromatogr. B: Anal. Technol. Biomed. Life Sci., 2014, 958, 75-82.

7 S. Ler, F. Lee and P. Gopalakrishnakone, J. Chromatogr. A, 2006, 1133, 1-12.

8 M. Pascale, G. Panzarini and A. Visconti, Talanta, 2012, 89, 231-236.

9 M. E. Flores-Flores and E. González-Peñas, J. Chromatogr. A, 2015, 1419, 37-44.

10 F. Soleimany, S. Jinap, A. Faridah and A. Khatib, Food Control, 2012, 25, 647-653.

11 W. Kong, X. Zhang, H. Shen, Z. Ou-Yang and M. Yang, Food Chem., 2012, 132, 574-581.

12 Y. Li, X. Luo, S. Yang, X. Cao, Z. Wang, W. Shi and S. Zhang, J. Agric. Food Chem., 2014, 62, 1492-1497.

13 Q. Deng, M. Qiu, Y. Wang, P. Lv, C. Wu, L. Sun, R. Ye, D. Xu, Y. Liu and R. Gooneratne, Ecotoxicol. Environ. Saf., 2017, 142, 441-447.

14 I. M. Khan, S. Zhao, S. Niazi, A. Mohsin, M. Shoaib, N. Duan, S. Wu and Z. Wang, Sens. Actuators, B, 2018, 277, 328-335.
15 A. C. R. Porricelli, V. Lippolis, S. Valenzano, M. Cortese, M. Suman, S. Zanardi and M. Pascale, Food Analytical Methods, 2016, 9, 3310-3318.

16 C. Wang, X. Li, T. Peng, Z. Wang, K. Wen and H. Jiang, Food Control, 2017, 77, 1-7.

17 D. Kong, L. Liu, S. Song, S. Suryoprabowo, A. Li, H. Kuang, L. Wang and C. Xu, Nanoscale, 2016, 8, 5245-5253.

18 R. Bilan, F. Fleury, I. Nabiev and A. Sukhanova, Bioconjugate Chem., 2015, 26, 609-624.

19 M. Ren, H. Xu, X. Huang, M. Kuang, Y. Xiong, H. Xu, Y. Xu, H. Chen and A. Wang, ACS Appl. Mater. Interfaces, 2014, 6, 14215-14222.

20 P. Zhang, H. Lu, J. Chen, H. Han and W. Ma, Theranostics, 2014, 4, 307-315.

21 D. Y. He, Z. Z. Wu, B. Cui, E. B. Xu and Z. Y. Jin, Food Analytical Methods, 2019, 12, 625-632.

22 Z. W. Qie, W. L. Yan, Z. C. Gao, W. Meng, R. Xiao and S. Q. Wang, Anti-BSA antibody based sensitive and universal combined immunochromatographic assay for chloramphenicol and aflatoxin M1, Anal. Chem., 2019, 91, 9530-9537.

23 X. Huang, Z. P. Aguilar, H. Li, W. Lai, H. Wei, H. Xu and Y. Xiong, Anal. Chem., 2013, 85, 5120-5128.

24 C. Li, W. Luo, H. Xu, Q. Zhang, H. Xu, Z. P. Aguilar, W. Lai, H. Wei and Y. Xiong, Food Control, 2013, 34, 725-732.

25 V. Semenova, J. Schiffer, E. Steward-Clark, S. Soroka, D. Schmidt, M. Brawner, F. Lyde, R. Thompson, N. Brown and L. Foster, J. Immunol. Methods, 2012, 376, 97-107.

26 Y. Bai, Z. Liu, Y. Bi, X. Wang, Y. Jin, L. Sun, H. Wang, C. Zhang and S. Xu, J. Agric. Food Chem., 2012, 60, 1161811624.

27 X. Chen, Y. Huang, N. Duan, S. Wu, Y. Xia, X. Ma, C. Zhu, Y. Jiang and Z. Wang, J. Agric. Food Chem., 2014, 62, 10368-10374.

28 K. Schulz, C. Pöhlmann, R. Dietrich, E. Märtlbauer and T. Elßner, Front. Chem., 2019, 7, 31. 